\title{
Genç Sürücülerde Sürücü Becerileri ve Sürücü Davranışları Arasındaki İlişki
}

\author{
İbrahim Öztürk1,2*, Türker Özkan¹ \\ ${ }^{1}$ Güvenlik Araştırma Birimi, Psikoloji Bölümü, Orta Doğu Teknik Üniversitesi, Ankara Türkiye. \\ ${ }^{2}$ Psikoloji Bölümü, Çanakkale Onsekiz Mart Üniversitesi, Çanakkale Türkiye.
}

$\ddot{O} \mathbf{z}$

Karayolu trafik kazaları dünya genelinde tüm yaş grupları, özellikle genç sürücüler, için önde gelen halk sağlı̆̆ı problemlerinden biridir. Sürücü davranışları ve sürücü becerileri kazaya etki eden önemli insan faktörlerindendir. Özellikle sürücü davranışları ve sürücü becerileri arasındaki ilişkinin incelenmesi trafik ortamındaki insan faktörlerinin doğası ile ilgili detaylı bilgi sunmaktadır. Bu çalışmada, genç sürücülerde sürücü davranışları ve sürücü becerileri arasındaki ilişki incelenmiştir. Çalışma kapsamında sürücü becerileri özbildirim yöntemi kullanılarak sürücü davranışları hem özbildirim hem de sürüş simülatörü kullanılarak ölçülmüştür. Sonuçlar algısal-motor becerilerin, ihlaller ve sürüş simülatöründeki farklı yollardaki hız davranışılla pozitif ilişkili olduğunu gösterirken; güvenlik becerilerinde bu ilişkinin negatif olduğunu göstermiştir. Yapılan aşamalı regresyon analizlerine göre, güvenlik becerileri ihlalleri ve hız davranışlarını negatif olarak yordamaktadır. Ayrıca, hem algısal-motor hem de güvenlik becerileri olumlu sürücü davranışlarını pozitif olarak yordamıştır. Çalışma kapsamında alanyazında ilk defa sürücü becerileri ve sürücü davranışları arasındaki ilişki hem özbildirim hem de sürüş simülatörü kullanılarak Türkiye'de genç sürücü örnekleminde çalışılmıştır. Sonuçlar genç sürücülerde sürücü davranışları ve sürücü becerileri arasındaki ilişki açısından detaylı bilgi sunmaktadır.

Anahtar Kelimeler: sürücü davranışları, sürücü becerileri, genç sürücüler, sürüş simülatörü, trafik psikolojisi

\section{The Relationship between Driving Skills and Driver Behaviors among Young Drivers}

\begin{abstract}
Road traffic accidents are one of the leading public health problem for all over the world and for all age groups, especially for young drivers. Driver behaviors and driving skills are important human factors components for these accidents. Examining the relationship between driver behaviors and driving skills provides detailed information regarding the nature of human factors in traffic settings. In the current study, the relationship between driving skills and driver behaviors was investigated among young drivers. Driving skills were measured by using selfreports and driver behaviors were measured by using both self-reports and driving simulator. The results showed that perceptual-motor skills were positively correlated and safety skills were negatively correlated with violations and speeding behaviors at different roads in driving simulator. According to hierarchical regression analysis, safety skills were negatively related to violations and speeding behaviors. Both perceptual-motor skills and safety skills were positively related to positive driver behaviors. For the first time in the literature, the relationship between driving skills and driver behaviors were measured by using both self-reports and driving simulator among young drivers in Turkey. The results provided detailed understanding regarding the relationship between driver behaviors and driving skills among young drivers.
\end{abstract}

Keywords: driver behaviors, driving skills, young drivers, driving simulator, traffic psychology

\footnotetext{
* Illetişim / Contact: İbrahim Öztürk, Güvenlik Araştırma Birimi, Psikoloji Bölümü, Orta Doğu Teknik Üniversitesi, Ankara Türkiye.E-Posta / Email: ibrahmoztrk@gmail.com

Gönderildiği tarihi / Date submitted: 24.04.2018, Kabul edildiği tarih / Date accepted: 25.06.2018

Alıntı / Citation: Öztürk, İ. ve Özkan, T. (2018). Genç Sürücülerde Sürücü Becerileri ve Sürücü Davranışları Arasındaki İlişki. Trafik ve Ulaşım Araştırmaları Dergisi, 1(2), 1-15.
} 


\section{Genç Sürücülerde Sürü cü Becerileri ve Sürücü Davranışları Arasındaki İlişki}

Karayolu trafik kazaları dünyanın birçok ülkesinde önde gelen halk sağlı̆̆ problemlerinden biridir. $\mathrm{Bu}$ kazalar sonucunda her yıl ortalama 1.25 milyon insan hayatın kaybetmekte ve milyonlarca insan yaralanmaktadır. Yine Dünya Sağlık Örgütü'nün (DSÖ) verilerine göre kazaların büyük bir çoğunluğu Türkiye gibi orta ve düşük gelir seviyesindeki ülkelerde gerçekleşmektedir (2015a). Türkiye'deki duruma bakıldığında ise 2006 y1lından itibaren ölümlü ve yaralanmalı trafik kazalarının sayısının giderek arttığı görülmektedir (TÜİK, 2016).

Trafik kazalarının nedenleri araştırıldığında insan faktörünün \%57 oranında ana tek etken ve \%90'nın üstünde bir oranda etken faktörlerden biri olarak trafik kazalarına etki ettiği bulunmuştur (Lewin, 1982; Treat ve ark., 1977). Türkiye'de meydana gelen trafik kazalarının \%90'ından fazlasında insan hatasının, özellikle sürücü hatasının, etken ana faktör olduğu raporlanmıştır (TÜİK, 2016). Trafik güvenliği ile ilgili yapılan çalışmalarda insan faktörleri genellikle iki ayrı faktör olarak ele alınmıştır. Bu faktörlerden ilki olan sürücü davranışları, sürücülerin bireysel sürüş tarzlarına odaklanarak sürücülerin trafikte neler yaptığ 1 (gösterdiği davranışlar) olarak tanımlanırken, sürücü becerileri ise sürücülerin neler yapabileceklerine (potansiyelleri) odaklanmaktadır (Elander, West ve French, 1993; Parker ve Stradling, 2001).

Yaş grupları incelendiğinde ise genç sürücülerin yaşlı sürücülere göre karayolu trafik kazalarına daha fazla maruz kaldığı ve daha fazla risk teşkil ettiği görülmektedir (DSÖ, 2015a; Sümer, Özkan ve Lajunen, 2006). Trafik güvenliğine ilişkin en önemli problemlerden biri genç sürücülerin yüksek risk teşkil etmesi ve trafik kazalarına daha fazla maruz kalmasıdır (Bener ve Crundall, 2008; Weiss, Kaplan ve Prato, 2014). Trafik kazaları genç bireylerdeki ölüm nedenleri arasında birinci sırada yer almaktadır (DSÖ, 2015b). Buradan da görüldüğü üzere, genç sürücüler trafik kazalarında hem etkilenen hem de etkileyen bir grup olarak büyük bir öneme sahiptir. Bu çalışma kapsamında genç sürücülerde sürücü davranışları ve sürücü becerileri arasındaki ilişkinin araştırılması amaçlanmaktadır.

\subsection{Sürücü Becerileri}

Sürücü becerileri, sürücülerin trafikte neler yapabileceklerine odaklanmaktadır (Elander et al., 1993; Parker ve Stradling, 2001) ve Lajunen ve Summala (1995) tarafindan algisal-motor becerileri (perceptual-motor skills) ve güvenlik becerileri (safety skills) olarak iki ayrı faktörde incelenmektedir. Algısal-motor becerileri sürücülerin aracı kontrol etmek gibi teknik sürüş becerilerine odaklanırken; güvenlik becerileri sürücülerin trafik kazalarından uzak durma ve güvenli sürüş becerilerine odaklanmaktadır (Lajunen ve Summala, 1995). Sürücü becerileri, Lajunen ve Summala (1995) tarafindan geliştirilen ve Almanya (Ostapczuk, Joseph, Pufal ve Musch, 2017), Avustralya (Lajunen, Corry, Summala ve Hartley, 1998a) ve Türkiye (Sümer ve ark., 2006) gibi birçok ülkede güvenilir ve geçerli bulunan Sürücü Becerileri Ölçeği (SBÖ) ile ölçülmektedir. Bu kapsamda sürücülerden belirli özelliklerde kendi sürücülüklerinin güçlü ve zayıf yanlarını değerlendirmeleri istenmektedir (Lajunen, Corry, Summala ve Hartley, 1998a).

Genel olarak algısal-motor becerileri ve güvenlik becerileri arasındaki ilişkiye bakıldığında, algısal-motor becerileri ile güvenlik becerileri güvensiz trafik çıktıları ile asimetrik bir ilişki göstermektedir. $\mathrm{Bu}$ asimetrik ilişkiye göre trafik cezaları ile algısal-motor beceriler arasında olumlu bir ilişki varken güvenlik becerileri ile olumsuz bir ilişki bulunmuştur (Sümer ve ark., 2006).

Sürücü becerilerinin birçok demografik değişkene göre farklılık gösterdiği bulunmuştur (Delhomme, 1991; Lajunen ve Summala, 1995; Özkan ve Lajunen, 2006). Martinussen, Møller ve Prato (2014) tarafından yapılan çalışmada yaş ile algısal-motor becerilerin negatif, güvenlik becerilerinin ise pozitif ilişki gösterdiği görülmüştür. Sümer ve ark. (2006) tarafından yapılan

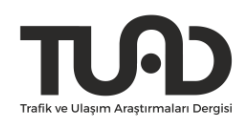


çalışmada genç sürücülerin kendilerini özellikle sürücü becerilerinde abartılı değerlendirme eğilimi gösterdiği bulgulanmıştır. Lajunen ve Summala (1995) tecrübeli sürücülerin daha fazla algısal-motor becerileri ve daha az güvenlik becerileri raporladığını göstermiştir. Yine Ostapczuk ve ark. (2017) tarafından yapılan çalışmada tecrübeli ve yaşlı sürücülerin yüksek algısalmotor becerileri gösterirken güvenlik becerileri için bu farklılığın anlamlı olmadığı bulunmuştur. Cinsiyet açısından bakıldığında ise, bazı çalışmalarda sürücü becerileri için cinsiyet farklılığı bulunmazken (Lajunen ve Summala, 1995), bazı çalışmalarda erkek sürücülerin daha fazla algısalmotor becerileri ve kadın sürücülerin daha fazla güvenlik becerileri raporladığ bulunmuştur (Martinussen ve ark., 2014; Özkan ve Lajunen, 2006).

\subsection{Sürücü Davranışları}

Sapkın sürücü davranışları, sürüş esnasında görülen hatalar ve ihlaller gibi birçok sürücü davranışını içermektedir. Bu sapkın sürücü davranışları Reason, Manstead, Stradling, Baxter ve Campbell (1990) tarafından belirli bir sınıflandırma sistemine göre hazırlanmış Sürücü Davranışları Ölçeği (SDÖ) ile ölçülmektedir. Sürücü davranışlarının ölçülmesi açısından bakıldığında SDÖ birçok ülkede en sık kullanılan özbildirim ölçeği olduğu görülmektedir (de Winter ve Dodou, 2010). SDÖ hem sapkın sürücü davranışlarının belirlenmesinde hem de trafik kazalarına dahil olmanın yordanmasında kullanılmaktadır (Cordazzo, Scialfa, Bubric ve Ross, 2014).

SDÖ sapkın sürücü davranışlarını sınıflandıran bir sisteme göre geliştirilmiştir. Bu kapsamda sürücü davranışlarının hatalar ve ihlaller olmak üzere iki temel farklı kökene sahip olduğu belirtilmiştir. Hatalar planlanan davranışların beklenen sonuçları başarılı olarak gerçekleştirememesi olarak tanımlanırken, ihlaller potansiyel tehlikeli bir sistemde güvenli süreçlerin devam etmesini sağlayacak uygulamalardan kasitlı olarak sapma olarak tanımlanmaktadır (Reason ve ark., 1990). af Wåhlberg, Dorn ve Kline (2011) tarafından belirtildiği üzere SDÖ'nün birçok farklı faktör yapısı ve madde içeriğiyle kullanıldığı bulunmuştur. Ancak genel olarak bakıldığında, SDÖ'nün faktör yapısının kasıtlı (ihlaller, violations) ve kasıtsız (hatalar, errors) sapkın sürücü davranışlarını iyi bir şekilde ayırdığ 1 görülmektedir (Martinussen, Hakamies-Blomqvist, Møller, Özkan ve Lajunen, 2013).

Sürücü davranışlarına etki eden faktörlere bakıldığında ise, yaşın ihlaller ve hatalar ile negatif bir ilişki gösterdiği bulunmuştur (Martinussen ve ark., 2014). Genç sürücülerin daha fazla ihlal (Rowe, Roman, McKenna, Barker ve Poulter, 2015) ve hata (de Winter ve Dodou, 2010) raporladığı görülmektedir. Başka bir deyişle, yaşın artmasıyla birlikte ihlallerin de azaldığı görülmektedir. Ayrıca, ihlallerin genç sürücülerde kazalara dahil olmayı daha iyi yordadığı bulunmuştur (de Winter ve Dodou, 2010). Guého, Granié ve Abric (2014) tarafindan trafiğe daha fazla maruz kalmanın, tecrübenin, hatalar ile negatif ilişki gösterdiği, tecrübesiz sürücülerin daha fazla hata raporladığı belirtilmiştir. Tecrübesiz sürücüler dikkat dağıtıcı faktörlerden veya tecrübesizlikten kaynaklı hataları daha fazla deneyimlemektedir (Shi, Bai, Ying ve Atchley, 2010). Bunun aksine, daha fazla kilometre kat eden, daha tecrübeli, sürücülerin daha fazla ihlal yaptığ görülmektedir (de Winter ve Dodou, 2010). Haftalık olarak kat edilen kilometre miktarı incelendiğinde ise dikkatsizlik veya tecrübesizlikten kaynaklanan hataların daha az ve sıradan ve agresif ihlallerin daha fazla olduğu görülmektedir (Guého ve ark., 2014). Cinsiyet ve sürücü davranışları arasındaki ilişkiye bakıldığında ise erkek sürücülerin, özellikle de genç erkek sürücülerin, daha fazla sıradan ve agresif ihlal gösterdiği bulunmuştur (Reason ve ark., 1990; Rowe ve ark., 2014). Bunun aksine, kadın sürücüler ise daha fazla hata göstermektedir (Guého ve ark., 2014). Genel olarak bakıldığında ise erkeklerin daha fazla sapkın sürücü davranışı gösterdiği görülmektedir (Rowe ve ark., 2015).

SDÖ ve alt boyutları özbildirim trafik kazaları ile anlamlı bir ilişki gösterdiği görülmektedir (af Wåhlberg ve ark., 2011; Cordazzo ve ark., 2014). Hatalar ve ihlaller trafik kazalarını eşit seviyede pozitif olarak yordamaktadır (Cordazzo ve ark., 2014; de Winter ve Dodou, 2010). Özellikle ihlaller

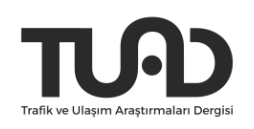


çeşitli demografik değişkenler kontrol edildikten sonra bile trafik kazalarını yordamaya devam etmektedir. Bu yüzden, ihlallerin kültür, dil ve sürüş ortamına ait durumlardan bağımsız bir değişken olduğu öne sürülmektedir (Gras ve ark., 2006).

Sapkın sürücü davranışlarına ek olarak, Özkan ve Lajunen (2005) tarafindan olumlu sürücü davranışları boyutu SDÖ'ye eklenmiştir. Olumlu sürücü davranışları trafik ortamını ve diğer yol kullanıcılarını gözetme niyetiyle gerçekleştirilen, nazik olmak ve diğerlerine yardım etmek gibi, davranışları içermektedir (Özkan ve Lajunen, 2005). Guého ve ark. tarafından da belirtildiği üzere bu davranışların çalışılması özellikle çok sık çalışılmadıkları için önemlidir. Olumlu sürücü davranışları ihlaller ve hatalar ile negatif ilişki gösterirken genç ve tecrübesiz sürücüler tarafından daha az gösterildiği görülmüştür (Guého ve ark., 2014; Özkan ve Lajunen, 2005).

Sürücü davranışlarının belirlenmesinde SDÖ gibi özbildirim yöntemlerinin kullanımına ek olarak sürüş simülatörleri de özellikle deneysel çalışmalarda kullanılmaktadır (Carsten ve Jamson, 2011). Deneysel kontrol sağlaması gibi birçok teorik ve pratik nedenden ötürü sürüşs simülatörleri diğer ölçüm yöntemlerine karşı yeni bir alternatif olarak değerlendirilmektedir (Bella, 2008; Brooks ve ark., 2010; Carsten ve Jamson, 2011; Helman ve Reed, 2015). Sürüş simülatörleri sürücülerin trafikteki gerçek performanslarıyla ilişkili bulunmuştur (Casutt, Martin, Keller ve Jäncke, 2014). Sürüş simülatörleri özellikle de hız davranışının ölçülmesinde güvenilir bir yöntem olarak görülmektedir (Bella, 2008; Helman ve Reed, 2015). Helman ve Reed (2015) tarafindan yapılan çalışmada sürüş simülatöründeki hız davranışının SDÖ’nin ihlaller boyutuyla anlamlı ilişki gösterdiği bulunmuştur. Calvi, Benedetto ve de Blasiis (2015) tarafında yapılan çalışmada ise sürüş simülatöründe trafiğgin akışının sürücülerin hız davranışını etkilediği görülmüştür. Simülatördeki hız davranışına ek olarak sapkın sürücü davranışlarında da en önde gelen davranışlardan biri hız davranışıdır (Hassan, Shawky, Kishta, Garib ve Al-Harthei, 2017). Goldenbeld ve van Schagen'e göre (2007) sürücüler genel olarak hız limitlerinin üstünde araç kullanmayı tercih etmektedir. $\mathrm{Bu}$ hız tercihlerini yol ve yolun çevresindeki diğer öğeler de etkilemektedir.

\subsection{Sürücü Becerileri ve Sürücü Davranışları Arasındaki İlişki}

Alanyazında sürücü becerileri ve sürücü davranışlarının birçok değişkenle ilişkisi incelenmesine rağmen çok az çalışmada bu değişkenler bir arada incelenmiştir. Bu ilişki açısından, güvenlik becerisi düşük sürücüler daha fazla ihlal ve riskli sürücü davranışları göstermektedir (Sümer ve ark., 2006; Sümer ve Özkan, 2002). Martinussen ve ark. (2014) tarafindan yapılan bir çalışmada ise algısal-motor becerileri yüksek olan sürücülerin daha fazla ihlal ve daha az hata gösterirken güvenlik becerileri yüksek olan sürücüler ise daha az ihlal ve hata gösterdiği bulunmuştur. Aynı şekilde, Lajunen, Parker ve Stradling (1998b) tarafından da güvenlik becerilerinin saldırgan ve sıradan ihlaller ile anlamlı ve negatif bir ilişki gösterdiği bulunmuştur. Kendisini ortalama bir sürücüden daha becerikli gören sürücülerin riskli durumları daha az tehlikeli değerlendirebileceği veya daha kolay idare edebileceklerini düşündüğünden dolayı daha fazla riskli davranış gösterdiği öne sürülmektedir (Martinussen ve ark., 2014; Reason ve ark., 1990). Martinussen ve ark. tarafından, algısal-motor ve güvenlik becerileri yüksek sürücülerin sapkın sürücü davranışlarını daha az gösterdiği raporlanmıştır. Buna karşın, algısal-motor becerileri yüksek güvenlik becerileri düşük sürücülerin ise daha fazla ihlal yaptığ bulunmuştur (Martinussen ve ark., 2014).

\section{4. Çalışmanın Amacı}

Belirtilen bu durumlar göz önüne alındığında trafik ortamında genç sürücülerin, özellikle de sürücü davranışları ve sürücü becerileri arasındaki ilişkinin araştırılmasının trafik güvenliği için önemi görülmektedir. Bu kapsamda çalışmanın amacı özbildirim sürücü becerileri ile özbildirim sürücü davranışları ve sürüş simülatöründeki sürücü davranışları arasındaki ilişkinin

\section{TQD}


incelenmesidir. Alanyazında ilk defa sürücü becerileri ve sürücü davranışları hem özbildirim hem de sürüş simülatörü kullanılarak Türkiye örnekleminde araştırılmıştır.

\section{Yöntem}

\subsection{Katılımcilar}

Çalışmaya toplam 80 sürücü, 40 erkek ve 40 kadın, katılmıştır. 1 erkek ve 1 kadın katılımcı kat edilen kilometre konusunda uçdeğerler gösterdiği için ilerleyen analizlere dahil edilmemiştir. Katılımcılar $19-25$ yaş arasında $(M=22.28, S S=1.63)$ yer almaktadır. Bütün katılımcılar B sınıfı ehliyet sahibidir. Son bir yılda $2500 \mathrm{~km}$ ile $40000 \mathrm{~km}$ arası yol kat etmişlerdir $(M=11218.18$, $S S=35116.81)$.

\subsection{Veri Toplama Araçları}

\subsubsection{Sürücü Becerileri Ölçeği.}

Sürücü becerilerinin ölçülmesi amacıyla Lajunen ve Summala (1995) tarafından geliştirilen SBÖ kullanılmıştır. Ölçek algısal-motor becerileri ve güvenlik becerileri olmak üzere 2 boyuttan oluşmakta ve 1, çok zayıf, ile 5, çok güçlü, arasında 5'li Likert tipte değerlendirilmektedir. Yapılan faktör analizi sonucunda (Öztürk, 2017) algısal-motor becerileri boyutunun .86 iç tutarlılık katsayısıyla 13 maddeden oluştuğu ve güvenlik becerileri boyutunun .76 iç tutarlılık katsayısıyla 7 maddeden oluştuğu görülmüştür.

\subsubsection{Sürücü Davranışları Ölçeği.}

Sürücü davranışlarının özbildirim yöntemiyle ölçülmesi amacıyla Reason ve ark. (1990) tarafindan geliştirilen SDÖ kullanılmıştır. Ölçek toplamda 28 maddeden oluşmakta ve 6'lı Likert tipte (0, Hiçbir zaman - 5, Her zaman) değerlendirilmektedir. Ölçeğin Türkçe'ye uyarlaması Sümer, Lajunen ve Özkan (2002) tarafından yapılmıştır (Sümer ve Özkan, 2002). Yapılan faktör analizi sonucunda ölçeğin hatalar ve ihlaller olmak üzere iki boyut gösterdiği bulunmuştur (Öztürk, 2017). Hatalar 12 maddeden oluşmakta ve .75 iç tutarlılık katsayısı göstermektedir. İhlaller 13 maddeden oluşmakta ve .77 iç tutarlılık katsayısı göstermektedir. Buna ek olarak Özkan ve Lajunen (2005) tarafından geliştirilen olumlu sürücü davranışları da 14 madde ile ölçülmüş̧ür. Ölçeğin iç tutarlılık katsayısı .55 olarak bulunmuştur.

\subsubsection{Demografik Bilgi Formu.}

Demografik bilgi formunda katılımcılardan genel ve sürüş ile alakalı demografik bilgileri (yaş, cinsiyet, son bir yılda kat edilen kilometre vb.) içeren sorular cevaplamaları istenmiştir.

\subsubsection{Sürüş Simülatörü.}

Sürücü davranışlarının sürüş simülatöründe ölçülmesi amacıyla STISIM Drive M100W (STISIM Drive ${ }^{\circledR}$ Model 100 Wide Field-of-View Complete System) modeli sürüş simülatörü kullanılmıştır. Katılımcılardan 2 senaryo tamamlamaları istenmiştir.

\subsubsection{Test Senaryosu.}

Katılımcıların sürüş simülatörü ortamına alışması ve simülatör hastalığı yaşayıp yaşamadıklarının belirlenmesi adına 3 kilometre uzunluğunda 4 şeritli bir yol içeren bir test senaryosunda katılımcılardan araç kullanmaları istenmiştir. Test senaryosunun bitiminde katılımcılara hazır olup olmadıkları ve simülatör hastalığı semptomları (baş dönmesi, mide bulanması vb.) gösterip göstermedikleri sorulmuştur. Simülatör sistemine alışma konusunda hazır hissetmeyen katılımcılarla ikinci bir test sürüşü gerçekleştirilmiştir. Ardından simülatör hastalığı göstermeyen

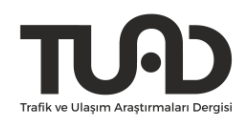


katılımcılarla deney senaryosuna geçilmiştir. Bu çalışmada hiçbir katılımcı simülatör hastalığı göstermemiştir.

\subsubsection{Deney Senaryosu.}

Deney senaryosu toplam 10 kilometre uzunluğunda ve 2 ve 4 şeritli yollardan oluşmaktadır. Hız limitleri yolun ve yerleşim yerinin özelliklerine göre $50 \mathrm{~km} / \mathrm{s}, 82 \mathrm{~km} / \mathrm{s}$ ve $90 \mathrm{~km} / \mathrm{s}$ olarak belirlenmiştir. Yerleşim yeri olan bölgelerde park halindeki araçlar, kaldırımdan yürüyen yayalar, trafik 1şıkları, karşıdan karşıya geçen yayalar gibi yol ögeleri de yer almaktadır. Tüm senaryo boyunca yolun iki tarafında da park halinde ve hareket eden araçlar görülmektedir.

Yol toplamda 4 bölümden oluşmaktadır. Birinci bölüm yolun 0. ile 4200. metreleri arasında yer alan 4 şeritli yerleşim yeri yoludur. Bu bölgede hız limiti $82 \mathrm{~km} / \mathrm{s}$ olarak belirlenmiştir. İkinci bölüm yolun 4200 . ve 5600. metreleri arasında yer alan 4 şeritli yerleşim yeri yoludur. Bu bölgede hız limiti $90 \mathrm{~km} / \mathrm{s}$ olarak belirlenmiştir. Üçüncü bölüm yolun 5600. ve 8100. metreleri arasında yer alan 4 şeritli yerleşim yeri yoludur. Bu bölgede hız limiti $82 \mathrm{~km} / \mathrm{s}$ olarak belirlenmiştir. Son olarak dördüncü bölüm yolun 8100 . ve 10000. metreleri arasında yer alan 2 şeritli virajlı kırsal alan yoludur. Bu bölgede hız limiti $50 \mathrm{~km} / \mathrm{s}$ olarak belirlenmiştir. Bütün yol ve her yol bölümü için sürücülerin ortalama hız hesaplanmıştır.

\subsection{Süreç}

Orta Doğu Teknik Üniversitesi Uygulamalı Etik Araştırma Merkezi'nden alınan etik onay sonrasında çalışma sosyal medya ağları üzerinden duyurulmuştur. Çalışma ODTÜ - TSK MODSIMMER Binası İnsan Faktörü Laboratuvarında gerçekleştirilmiştir. Katılımcılar sırasıyla test ve deney senaryosunu tamamlamış ve ölçekleri doldurmuşlardır. Bu çalışma büyük bir proje kapsamında ve ilk yazarın yüksek lisans tezi kapsamında gerçekleştirilmiştir. Bütün proje bir katılımcı için yaklaşık 2 saat sürmüş ve batarya tüm katılımcılara aynı sırada uygulanmıştır. Katılımcılara 60 TL ödeme yapılmıştır.

\section{Bulgular}

\subsection{Korelasyon Analizleri}

Çalışma kapsamında değişkenler arasındaki ilişkinin incelenmesi amacıyla iki yönlü korelasyon analizi yapılmıştır (Tablo 1.). Genç sürücülerde, son bir yılda kat edilen kilometre ihlaller $(r=.473, p<.01)$ ve algısal-motor becerileri $(r=.225, p<.05)$ ile pozitif ilişki gösterirken güvenlik becerileri $(r=-.395, p<.01)$ ile negatif ilişki göstermiştir. Ayrıca, ihlaller sürüş simülatöründeki ortalama hız davranışınlar .50 'nin üzerinde pozitif ilişki gösterirken algısal-motor beceriler de aynı şekilde ortalama hız davranışıyla .28'in üzerinde pozitif ilişki göstermiştir. Buna karşılık, güvenlik becerileri genel ve tüm bölümlerdeki ortalama hız davranışıyla .26'nın üzerinde negatif ilişki göstermiştir. Algısal-motor becerileri, ihlaller ( $r=$ $.377, p<.01)$ ve olumlu sürücü davranışları $(r=.403, p<.01)$ ile pozitif ilişki gösterirken hatalar $(r=-.253, p<.05)$ ile negatif ilişki göstermiştir. Güvenlik becerileri olumlu sürücü davranışları $(r=.261, p<.05)$ ile pozitif ilişki gösterirken, ihlaller $(\mathrm{r}=-.575, p<.01)$ ile negatif ilişki göstermiştir. 
Tablo 1. Değişkenler arası korelasyon analizleri

\begin{tabular}{|c|c|c|c|c|c|c|c|c|c|c|c|c|c|c|}
\hline & Değişken & 1 & 2 & 3 & 4 & 5 & 6 & 7 & 8 & 9 & 10 & 11 & 12 & 13 \\
\hline 1 & Yaş & 1 & & & & & & & & & & & & \\
\hline 2 & Cinsiyet & .095 & 1 & & & & & & & & & & & \\
\hline 3 & Son y1l km & .171 & .009 & 1 & & & & & & & & & & \\
\hline 4 & O. Hiz Toplam & -.054 & $-.300 * *$ & .189 & 1 & & & & & & & & & \\
\hline 5 & O. Hiz 1. Bölüm & -.043 & -.219 & .141 & $.952 * *$ & 1 & & & & & & & & \\
\hline 6 & O. Hiz 2. Bölüm & -.077 & $-.349 * *$ & .180 & $.943 * *$ & $.862 * *$ & 1 & & & & & & & \\
\hline 7 & O. Hiz 3. Bölüm & -.066 & $-.272^{*}$ & .207 & $.924 * *$ & $.791 * *$ & $.895^{* *}$ & 1 & & & & & & \\
\hline 8 & O. Hiz 4. Bölüm & -.022 & $-.388 * *$ & .221 & $.837 * *$ & $.697 * *$ & $.757 * *$ & $.782 * *$ & 1 & & & & & \\
\hline 9 & Hatalar & -.121 & -.025 & -.134 & .160 & .199 & .188 & .116 & .013 & 1 & & & & \\
\hline 10 & İhlaller & -.016 & -.030 & $.473 * *$ & $.565 * *$ & $.514 * *$ & $.520 * *$ & $.515 * *$ & $.562 * *$ & .109 & 1 & & & \\
\hline 11 & Olumlu Sürücü Dav. & -.064 & $-.235 * *$ & -.203 & .089 & .070 & .061 & .074 & .147 & -.135 & -.037 & 1 & & \\
\hline 12 & Algisal-motor Becerileri & .094 & $-.346 * *$ & $.225^{*}$ & $.325 * *$ & $.288 *$ & $.299 * *$ & $.281 *$ & $.368 * *$ & $-.253^{*}$ & $.377 * *$ & $.403 * *$ & 1 & \\
\hline 13 & Güvenlik Becerileri & -.038 & -.043 & $-.395 * *$ & $-.317 * *$ & $-.274 *$ & $-.266^{*}$ & $-.334 * *$ & $-.316 * *$ & .032 & $-.575 * *$ & $.261 *$ & -.109 & 1 \\
\hline
\end{tabular}

$* * p<.01, * p<.05$. 


\subsection{Aşamalı Regresyon Analizleri}

Sürücü becerileri ve sürücü davranışları arasındaki ilişkinin incelenmesi amacıyla aşamalı regresyon analizleri uygulanmıştır. Birinci aşamada yaş, cinsiyet ( $1=$ Erkek, $2=$ Kadın) ve son bir yılda kat edilen kilometre değişkenleri kontrol amacıyla girilmiştir. İkinci aşamada algısalmotor becerileri ve güvenlik becerileri modele dahil edilmiştir. Özbildirim sürücü davranışları ve sürüş simülatöründeki hız davranışları için ayrı ayrı olmak üzere 8 farklı aşamalı regresyon analizi uygulanmıştır.

\subsubsection{Sürücü Becerileri ve Özbildirim Sürücü Davranışları İlişkisi}

Sürücü becerileri ile özbildirim sürücü davranışları arasındaki ilişkinin araştırılması amacıyla hatalar, ihlaller ve olumlu sürücü davranışları için 3 farklı aşamalı regresyon analizi uygulanmıştır (Tablo 2.).

Hatalar için model anlamlı çıkmamıştır $(F(4,72)=1.65, p=.171)$ ve toplam varyansın \%8.4'ünü açıklamıştır $\left(R^{2}=.084\right)$. İhlaller için model anlamlı çıkmıştır $(F(4,72)=16.64, p<$ $.001)$ ve toplam varyansın $\% 48$ 'ini açıklamıştır $\left(R^{2}=.480\right)$. Son bir yılda kat edilen kilometre $(95 \%$ CI $[0.00,0.00])$ ve algisal-motor becerileri $(95 \%$ CI $[.12, .55])$ ihlalleri pozitif olarak yordarken güvenlik becerileri $(95 \%$ CI [-.64, -.27]) negatif olarak yordamaktadır. Son bir yılda daha fazla kilometre kat eden sürücüler, algısal-motor becerileri yüksek sürücüler ve güvenlik becerileri düşük sürücüler daha fazla ihlal raporlamıştır.

Olumlu sürücü davranışları için model anlamlı çıkmıştır $(F(4,72)=7.80, p<.001)$ ve toplam varyansın \%30.2'sini açıklamıştır $\left(R^{2}=.302\right)$. Algısal-motor becerileri $(95 \%$ CI $[.21, .59])$ ve güvenlik becerileri $(95 \%$ CI $[-.01, .34])$ olumlu sürücü davranışlarını pozitif olarak yordarken son bir yllda kat edilen kilometre $(95 \%$ CI $[0.00,0.00]$ ve cinsiyet $(95 \%$ CI $[-.42,-.01])$ negatif olarak yordamaktadır. Algısal-motor becerileri ve güvenlik becerileri yüksek sürücüler, son bir yılda daha az kilometre kat eden sürücüler ve erkek sürücüler daha fazla olumlu sürücü davranışı göstermiştir.

\subsubsection{Sürücü Becerileri ve Sürüş Simülatörü Hız Davranışları}

Sürücü becerileri ile sürüş simülatöründeki hız davranışları arasındaki ilişkinin araştırılması amacıyla tüm senaryo için ve dört farklı yol bölümündeki ortalama hız davranışları için 5 farklı aşamalı regresyon analizleri uygulanmıştır (Tablo 3.).

Tüm senaryo için ortalama hız davranışı için model anlamlı çıkmıştır $(F(4,72)=5.66, p=.001)$ ve toplam varyansın \%23.9'unu açılamıştır $\left(R^{2}=.239\right)$. Cinsiyet $(95 \%$ CI $[-19.36,-3.09])$ ve güvenlik becerileri (95\% CI [-16.61, -2.45]) tüm senaryodaki ortalama hız davranışını negatif olarak yordamıştır. Kadın sürücüler ve güvenlik becerileri yüksek sürücüler daha düşük ortalama hız davranış1 göstermiştir.

Yolun birinci bölümündeki ortalama hız davranışı için model anlamlı çıkmıştır $(F(4,72)=3.64$, $p=.009)$ ve toplam varyansın \%16.8'sini açıklamıştır $\left(R^{2}=.168\right)$. Bu bölümde sadece güvenlik becerileri (95\% CI [-19.03, -1.44]) ortalama hız davranışını negatif olarak yordamıştır. Güvenlik becerileri yüksek olan sürücüler daha düşük ortalama hız davranışı göstermiştir.

Yolun ikinci bölümündeki ortalama hız davranışı için model anlamlı çıkmıştır $(F(4,72)=5.28$, $p=.001)$ ve toplam varyansın \%22.7'sini açıklamıştır $\left(R^{2}=.227\right)$. Bu bölümde cinsiyet $(95 \% \mathrm{CI}$ $[-23.63,-5.77])$ ve güvenlik becerileri $(95 \%$ CI $[-16.52,-.59])$ ortalama hız davranışını negatif olarak yordamıştır. Kadın sürücüler ve güvenlik becerileri yüksek sürücüler daha düşük ortalama hız davranışı göstermiştir.

Yolun üçüncü bölümündeki ortalama hız davranışı için model anlamlı çıkmıştır $(F(4,72)=5.12$, $p=.001)$ ve toplam varyansın \%22.1'ini açıklamıştır $\left(R^{2}=.221\right)$. Bu bölümde cinsiyet $(95 \% \mathrm{CI}$

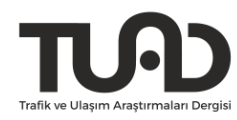


$[-19.24,-2.15])$ ve güvenlik becerileri (95\% CI $[-17.78,-2.81])$ ortalama hız davranışını negatif olarak yordamıştır. Kadın sürücüler ve güvenlik becerileri yüksek sürücüler daha düşük ortalama hız davranışı göstermiştir.

Yolun dördüncü bölümündeki ortalama hız davranışı için model anlamlı çıkmıştır $(F(4,72)=$ $8.00, p<.001)$ ve toplam varyansın \%30.8'ini açıklamıştır $\left(R^{2}=.308\right)$. Bu bölümde son bir yılda kat edilen kilometre (95\% CI [.00, .00]) ve algisal-motor beceriler (95\% CI [-.20, 13.43]) dördüncü bölümdeki ortalama hız davranışını pozitif olarak yordarken cinsiyet (95\% CI [-19.63, -6.02]) ve güvenlik becerileri $(95 \%$ CI $[-13.70,-1.89])$ negatif olarak yordamıştır. Erkek sürücüler, son bir yılda daha fazla kilometre kat eden sürücüler, algısal-motor becerileri yüksek sürücüler ve güvenlik becerileri düşük sürücüler daha yüksek ortalama hız göstermiştir. 
Tablo 2. DSI ve DBQ ile aşamalı regresyon analizleri

\begin{tabular}{|c|c|c|c|c|c|c|c|c|c|c|c|c|}
\hline \multirow[b]{2}{*}{ Değişkenler } & \multicolumn{4}{|c|}{ 1. Hatalar } & \multicolumn{3}{|c|}{ 2. İhlaller } & \multicolumn{5}{|c|}{ 3. Olumlu Sürücü Davranışları } \\
\hline & $R^{2}$ & $F \Delta$ & $\beta$ & $p$ & $R^{2}$ & $F \Delta$ & $\beta$ & $p$ & $R^{2}$ & $F \Delta$ & $\beta$ & $p$ \\
\hline 1. Demografik değişkenler & .018 & .688 & & & .225 & 10.757 & & & .096 & 3.916 & & \\
\hline Cinsiyet & & & -.017 & .884 & & & -.036 & .729 & & & -.234 & .038 \\
\hline 2. DSI & .084 & 2.585 & & & .480 & 17.675 & & & .302 & 10.652 & & \\
\hline Algisal-motor becerileri & & & -.280 & .027 & & & .294 & .002 & & & .453 & .000 \\
\hline Güvenlik becerileri & & & -.046 & .710 & & & -.455 & .000 & & & .227 & .038 \\
\hline
\end{tabular}

Df, F-test: 1. Așama = 2, 74; 2. Așama = 4, 72.

Tablo 3. DSI ve ortalama hız davranışları arasındaki aşamalı regresyon analizleri

\begin{tabular}{|c|c|c|c|c|c|c|c|c|c|c|c|c|c|c|c|c|c|c|c|c|}
\hline \multirow[b]{2}{*}{ Değişkenler } & \multicolumn{4}{|c|}{ 1. Ortalama Hız Toplam } & \multicolumn{4}{|c|}{ 2. Ortalama Hız 1. Bölüm } & \multicolumn{3}{|c|}{ 3. Ortalama Hız 2. Bölüm } & \multicolumn{4}{|c|}{ 4. Ortalama Hız 3. Bölüm } & \multicolumn{5}{|c|}{ 5. Ortalama Hız 4. Bölüm } \\
\hline & $R^{2}$ & $F \Delta$ & $\beta$ & $p$ & $R^{2}$ & $F \Delta$ & $\beta$ & $p$ & $R^{2}$ & $F \Delta$ & $\beta$ & $p$ & $R^{2}$ & $F \Delta$ & $\beta$ & $p$ & $R^{2}$ & $F \Delta$ & $\beta$ & $p$ \\
\hline $\begin{array}{l}\text { 1. Demografik } \\
\text { değişkenler }\end{array}$ & .125 & 5.291 & & & .066 & 2.629 & & & .155 & 6.797 & & & .117 & 4.898 & & & .201 & 9.322 & & \\
\hline Cinsiyet & & & -.299 & .008 & & & -.215 & .059 & & & -.351 & .002 & & & -.272 & .015 & & & -.390 & .000 \\
\hline Son yll kilometre & & & .192 & .082 & & & .143 & .206 & & & .183 & .091 & & & .209 & .059 & & & .225 & .034 \\
\hline 2. DSI & .239 & 5.400 & & & .168 & 4.404 & & & .227 & 3.332 & & & .221 & 4.835 & & & .308 & 5.529 & & \\
\hline Algisal-motor becerileri & & & .203 & .077 & & & .208 & .082 & & & .155 & .178 & & & .156 & .177 & & & .209 & .057 \\
\hline Güvenlik becerileri & & & -.301 & .009 & & & -.272 & .023 & & & -.242 & .036 & & & -.310 & .008 & & & -.281 & .010 \\
\hline
\end{tabular}




\section{Tartışma, Sonuç ve Öneriler}

Bu çalışmada genç sürücülerde sürücü becerileri ile özbildirim ve sürüş simülatöründeki sürücü davranışları arasındaki ilişki incelenmiştir. Trafik kazalarının toplumun her kesimi için tüm dünyada önemli bir halk sağlığı problemi olması ve genç sürücülerin bu kazalara yoğun bir şekilde maruz kalması ve sapkın sürücü davranışlarını diğer sürücülere kıyasla daha fazla göstermeleri çalışmanın bulgularının teorik ve uygulamadaki önemini göstermektedir. Bugüne kadar Türkiye'de bu konularda yapılan benzer çalışmalarda sürücü becerilerinin örtük ölçüm gibi farklı ölçüm yöntemleri (Özkan ve ark., 2013; Öztürk, 2017) ve farklı psikometrik ölçüm sistemlerindeki geçerliliği incelenmiştir (Amado, Koyuncu ve Kaça, 2013; 2015). Ancak, bu çalışma kapsamında Türkiye örnekleminde ilk defa sürücü becerileri ve sürücü davranışları arasındaki ilişki hem özbildirim hem de sürüş simülatörü kullanılarak araştırılmıştır. Yine alanyazında ilk defa sürücü davranışlarına olumlu sürücü davranışları da eklenerek sürücü becerileri ile olan ilişki araştırılmıştır.

Korelasyon bulgularına göre, Taubman-Ben-Ari, Eherenfreund-Hager ve Prato (2016) tarafindan da belirtildiği gibi erkek sürücüler ve tecrübeli sürücüler sürüş simülatöründe daha hızlı araç kullanmayı tercih etmektedir. Ayrıca, sürüş simülatöründe ortalama hızı yüksek olan sürücüler aynı zamanda daha fazla ihlal raporlamıştır. Genel olarak bakıldığında sürüş simülatöründeki farklı karakterdeki yollardaki hız davranışları ile ihlaller arasındaki pozitif ilişki alanyazını destekler niteliktedir (Helman ve Reed, 2015). Lajunen ve ark. (1998a) tarafından da belirtildiği üzere algısal-motor becerileri ve hız arasında pozitif ve güvenlik becerileri ve hız arasında negatif bir ilişki görülmektedir.

Aşamalı regresyon analizlerine bakıldığında, alanyazına paralel bir şekilde (Martinussen ve ark., 2014; Sümer ve ark., 2006; Sümer ve Özkan, 2002), algısal-motor beceriler ihlalleri pozitif olarak yordarken güvenlik becerileri negatif olarak yordamıştır. Genç sürücülerde ihlaller açısından bakıldığında algısal-motor becerileri ve güvenlik becerileri, Sümer ve ark. (2006) tarafından önerilen negatif sürüş çıktılarıyla gösterilen asimetrik ilişkiyi desteklemiştir. Ancak, bu asimetrik ilişkinin aksine olumlu sürücü davranışları için simetrik bir ilişki görülmektedir. Hem algısal-motor beceriler hem de güvenlik becerileri olumlu sürücü davranışlarını pozitif olarak yordamaktadır. Olumlu sürücü davranışlarının özellikleri düşünüldüğünde hem algısalmotor becerileri hem de güvenlik becerileri yüksek sürücülerin bu davranışları daha rahat ve güvenle gerçekleştirdiği öne sürülebilir.

Sürüş simülatöründeki ortalama hız davranışları incelendiğinde ise toplamda sadece güvenlik becerileri sürekli negatif olarak farklı karakteristik özellikler gösteren yollardaki ortalama hız davranışını yordamaktadır. Lajunen ve ark. (1998a) tarafından da belirtildiği gibi sadece güvenlik becerileri hız davranışlarının yordanmasında etken rol oynamıştır. Buna ek olarak, algısal-motor becerileri yolun sadece dördüncü bölümünde ortalama hız davranışını pozitif olarak yordamıştır. Bu yolun diğer yollarla karakteristik özellikleri kıyaslandığında sadece bu yolun tek şerit olması, yolun iki tarafında da trafik içermesi ve aralıklı virajlardan oluşması yolun karakteristik özelliklerinin sürücü beceriyle olan etkileşimini yansıtmaktadır. Sürüş simülatöründeki senaryonun içeriği sürücülerin hız davranışlarında değişiklik göstermesine neden olmaktadır (Calvi ve ark., 2015). Bu bulgular, yolun görece yoğun olmasının algısalmotor becerilerle etkileşime girerek sürücülerin hız davranışı konusunda farklılaşmasına neden olduğu şeklinde yorumlanabilir.

Bazı çalışmalarda genç erkek sürücülerin özbildirim sürücü becerileri konusunda tutarlı olmadığ1 yönünde bulgular olsa da (Martinussen ve ark., 2017), bu çalışmada algısal-motor becerileri, güvenlik becerileri ve diğer sürücü davranışları arasındaki ilişkilerin ilişkinin yönü açısından tutarlı olduğu görülmüştür. Çalışmanın sınırlılıklarına bakıldığında ise örneklemin

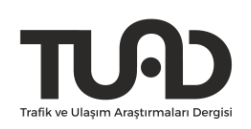


sadece genç sürücülerden oluşması genç sürücülerin davranışlarını anlama konusunda çalışmayı güçlü kılarken bulguların genellenebilirliğini sınırlamaktadır. Ayrıca, Carsten ve Jamson (2011) ve Lajunen ve Özkan (2011) tarafından da belirtildiği üzere özbildirim ve sürüş simülatörü kullanmanın metodolojik olarak sosyal istenir cevapların verilmesi ve gerçek sürücü davranışlarının uygun bir şekilde yansıtılmaması gibi getirdiği bazı sınırlılıklar mevcuttur. af Wåhlberg ve ark. (2011) SDÖ boyutlarının yine özbildirim yöntemiyle alınan kaza bilgileriyle ile anlamlı bir ilişki gösterdiğini ancak bu ilişkinin objektif veri ile devam etmediğini raporlamışlardır. Ancak, Lajunen ve Summala (2003) tarafından yapılan bir çalışmada sosyal istenirliğin SDÖ üzerindeki etkisinin zayıf olduğu bulunmuştur. Ayrıca Taubman-Ben-Ari ve ark. (2016) tarafından yapılan bir diğer çalışmada da özbildirim yöntemiyle elde edilen cevapların sürücülerin hem gerçek trafikteki hem de sürüş simülatöründeki davranışlarıyla pozitif olarak korelasyon gösterdiği görülmüştür.

Genel olarak bakıldığında ise çalışma hem teorik hem de pratik açıdan birçok önem taşımaktadır. Çalışmanın bulguları özellikle genç sürücülerde sürücü becerilerinin davranışlara olan etkisinin sürücü eğitimi sırasında vurgulanması gerektiğini öne çıkarmaktadır. Hız gibi trafik güvenliğine büyük etkileri olan sürücü davranışlarına algısal-motor becerilerinden ziyade güvenlik becerilerinin daha büyük etki göstermesi özellikle bu becerilere odaklanılmasını ve iyi ve becerikli sürücüyü tanımlarken bunlara önem verilmesini vurgulamaktadır. Gelecekteki çalışmalarda farklı yol özelliklerinin ve farklı yaş gruplarının çalışma sorusunda etkisinin araştırılması bulguların güvenilirlik ve geçerliliği için önemli olacaktır.

\section{Yazar Notları:}

Bu çalışma birinci yazarın yüksek lisans tezinin bir kısmını içermektedir. Ayrıntılı bilgi için "YOUNG DRIVER BEHAVIORS IN RELATIONS TO THE IMPLICIT AND EXPLICIT DRIVING SKILLS” isimli teze başvurabilirsiniz. 


\section{Kaynakça}

af Wåhlberg A., Dorn, L. ve Kline, T. (2011). The Manchester Driver Behaviour Questionnaire as a predictor of road traffic accidents. Theoretical Issues in Ergonomics Science, 12(1), 66-86. doi: 10.1080/14639220903023376

Amado, S., Koyuncu, M. ve Kaça, G. (2013). Türkiye'de Kullanılan Sürücü Psikoteknik Değerlendirme Test Sistemlerinin Karşılaştırılması ve Doğal Trafik Ortamındaki Sürücü Davranışları Gözlenerek Geçerliklerinin Değerlendirilmesi. TÜBİTAK Proje No: $110 \mathrm{~K} 428$.

Amado, S., Koyuncu, M. ve Kaça, G. (2015). Comparison of three systems for psychotechnical assessment used in Turkey. Transportation Research Part F: Traffic Psychology and Behavior, 32, 78-90. doi: 10.1016/j.trf.2015.04.013

Bella, F. (2008). Driving simulator for speed research on two-lane rural roads. Accident Analysis \& Prevention, 40, 1078-1087. doi: 10.1016/j.aap.2007.10.015

Bener, A. ve Crundall, D. (2008). Role of gender and driver behaviour in road traffic crashes. International Journal of Crashworthiness, 13(3), 331-336. doi: $10.1080 / 13588260801942684$

Brooks, J. O., Goodenough, R. R., Crisler, M. C., Klein, N. D., Alley, R. L., Koon, B. L., ..., Wills, R. F. (2010). Simulator sickness during driving simulator studies. Accident Analysis \& Prevention, 42, 788-796. doi: 10.1016/j.aap.2009.04.013

Calvi, A., Benedetto, A. ve de Blasiis, M. R. (2012). A driving simulator study of driver performance on deceleration lanes. Accident Analysis \& Prevention, 45, 195-203. doi: 10.1016/j.aap.2011.06.010

Carsten, O. ve Jamson, A. H. (2011). Driving simulators as research tools in traffic psychology. B. E. Porter (Ed.), Handbook of Traffic Psychology (pp.87-96). San Diego, CA: Elsevier.

Casutt, G., Martin, M., Keller, M. ve Jäncke, L. (2014). The relationship between performance in on-road driving, cognitive screening and driving simulator in older healthy drivers. Transportation Research Part F: Traffic Psychology and Behaviour, 22, 232-244. doi: 10.1016/j.trf.2013.12.007

Cordazzo, S. T. D., Scialfa, C. T., Bubric, K. ve Ross, R. J. (2014). The Driver Behaviour Questionnaire: A North American analysis. Journal of Safety Research, 50, 99-107. doi: 10.1016/j.jsr.2014.05.002

de Winter, J. C. F. ve Dodou, D. (2010). The Driver Beahviour Questionnaire as a predictor of accidents: A meta-analysis. Journal of Safety Research, 41, 463-470. doi: 10.1016/j.jsr.2010.10.007

Delhomme, P. (1991). Comparing one's driving with others': Assessment of abilities and frequency of offences. Evidence for a superior conformity of self-bias? Accident Analysis \& Prevention, 23(6), 493-508.

Dünya Sağl1k Örgütü (2015a). Global Status Report on Road Safety. Retrieved from: http://www.who.int/violence_injury_prevention/road_safety_status/2015/en/

Dünya Sağlık Örgütü (2015b). 10 facts on global road safety. Retrieved from: http://www.who.int/features/factfiles/roadsafety/facts/en/ 
Elander, J., West, R. ve French, D. (1993). Behavioral correlates of individual differences in road-traffic crash risk: an examination method and findings. Psychological Bulletin, 113(2), 279-294.

Goldenbeld, C. ve van Schages, I. (2007). The credibility of speed limits on $80 \mathrm{~km} / \mathrm{h}$ rural roads: The effects of road and person(ality) characteristics. Accident Analysis \& Prevention, 39, 1121-1130. doi: 10.1016/j.aap.2007.02.012

Gras, M. E., Sullman, M. J. M., Cunill, M., Planes, M., Aymerich, M. ve Font-Mayolas, S. (2006). Spanish drivers and their aberrant driving behaviors. Transportation Research Part F: Traffic Psychology and Behaviour, 9, 129-137. doi: 10.1016/j.trf.2005.09.004

Guého, L., Granié, M. A. ve Abric, J. C. (2014). French validation of a new version of the Driver Behavior Questionnaire (DBQ) for drivers of all ages and level of experiences. Accident Analysis \& Prevention, 63, 41-48. doi: 10.1016/j.aap.2013.10.024

Hassan, H. M., Shawy, M., Kishta, M., Garib, A. M. ve Al-Harthei, H. A. (2017). Investigation of drivers' behavior towards speeds using crash data and self-reported questionnaire. Accident Analysis \& Prevention, 98, 348-358. doi: 10.1016/j.aap.2016.10.027

Helman, S. ve Reed, N. (2015). Validation of the driver behaviour questionnaire using behavioural data from an instrumented vehicle and high-fidelity driving simulator. Accident Analysis \& Prevention, 75, 245-251. doi: 10.1016/j.aap.2014.12.008

Lajunen, T. ve Summala, H. (1995). Driving experience, personality, and skill and safetymotive dimensions in drivers' self-assessments. Personality and Individual Differences, 19(3), 307-318.

Lajunen, T., Corry, A., Summala, H. ve Hartley, L. (1998a). Cross-cultural differences in drivers' self-assessment of their perceptual-motor and safety skills: Australians and Finns. Personality and Individual Differences, 24(4), 539-550.

Lajunen, T., Parker, D. ve Stradling, S. G. (1998b). Dimensions of driving anger, aggressive and highway code violations and their mediation by safety orientation in UK drivers. Transportation Research Part F: Traffic Psychology and Behaviour, 1, 107-121.

Lewin, I. (1982). Driver training: a perceptual-motor skill approach. Ergonomics, 25, 917-924.

Martinussen, L. M., Hakamies-Blomqvist, L., Møller, M., Özkan, T. ve Lajunen, T. (2013). Age, gender, mileage, and the DBQ: The validity of the Driver Behavior Questionnaire in different driver groups. Accident Analysis \& Prevention, 52, 228-236. doi: 10.1016/j.aap.2012.12.036

Martinussen, L. M., Møller, M. ve Prato, C. G. (2014). Assessing the relationship between the Driver Behavior Questionnaire and the Driver Skill Inventory: Revealing sub-groups of drivers. Transportation Research Part F: Traffic Psychology and Behaviour, 26, 8291. doi: 10.1016/j.trf.2014.06.008

Ostapczuk, M., Joseph, R., Pufal, J. ve Musch, J. (2017). Validation of the German version of the Driver Skill Inventory (DSI) and the Driver Social Desirability Scales (DSDS). Transportation Research Part F: Traffic Psychology and Behaviour, 45, 169-182. doi: 10.1016/j.trf.2016.12.003

Özkan, T. ve Lajunen, T. (2005). A new addition to DBQ: Positive Driver Behaviours Scale. Transportation Research Part F: Traffic Psychology and Behaviour, 8, 355-368. doi: 10.1016/j.trf.2005.04.018

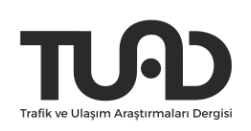


Özkan, T. ve Lajunen, T. (2006). What causes the differences in driving between young men and women? The effects of gender roles and sex on young drivers' driving behaviors and self-assessment of skills. Transportation Research Part F: Traffic Psychology and Behaviour, 9, 269-277. doi: 10.1016/j.trf.2006.01.005

Özkan, T., Doğruyol, B., Harma, M., Bıçaksız, P. ve Lajunen, T. (2013). Algı-motor ve güvenli sürücülük becerilerinin örtük ölçülmesi ve objektif performans testleri ile ilişkisi. TÜBİTAK Proje No:111K333.

Öztürk, İ. (2017). Young driver behaviors in relations to the implicit and explicit driving skills. (Yayınlanmamış Yüksek Lisans Tezi). Orta Doğu Teknik Üniversitesi, Ankara, Türkiye.

Parker, D. ve Stradling, S. (2001). Influencing Driver Attitudes and Behaviour, DETR Road Safety Research Report No.17, London: DETR.

Reason, J. T., Manstead, A., Stradling, S. G., Baxter, J. ve Campbell, K. (1990). Errors and violations on the road - A real distinction. Ergonomics, 33(10/11), 1315-1332.

Rowe, R., Roman, G. D., McKenna, F. P., Barker, E. ve Poulter, D. (2015). Measuring errors and violations on the road: A bifactor modeling approach 93 to the Driver Behavior Questionnaire. Accident Analysis \& Prevention, 74, 118-125. doi: 10.1016/j.aap.2014.10.012

Shi, J., Bai, Y., Ying, X. ve Atchley, P. (2010). Aberrant driving behaviors: A study of drivers in Beijing. Accident Analysis \& Prevention, 42, 1031-1040. doi: 10.1016/j.aap.2009.12.010

Sümer, N. ve Özkan, T. (2002). The role of driver behaviors, skills, and personality traits in traffic accidents. Journal of Turkish Psychology, 17(50), 1-22.

Sümer, N., Lajunen, T. ve Özkan, T. (2002). Sürücü davranışlarının kaza risklerindeki roller: İhlaller ve hatalar, Traffic and Road Safety International Congress, Gazi Üniversitesi, Ankara, Turkey, 8-12 May.

Sümer, N., Özkan, T. ve Lajunen, T. (2006). Asymmetric relationship between driving and safety skills. Accident Analysis \& Prevention, 38, 703-711. doi: 10.1016/j.aap.2005.12.016

Taubman-Ben-Ari, O., Eherenfreund-Hager, A. ve Prato, C. G. (2016). The value of self-report measures as indicators of driving behaviors among young drivers. Transportation Research Part F: Traffic Psychology and Behaviour, 39, 33-42. doi: 10.1016/j.trf.2016.03.005

Treat, J. R., Tumbas, N. S., McDonald, S. T., Shinar, D., Hume, R. D., Mayer, R. E., Stanisfer, R. L. ve Castellan, N. J. (1977). Tri-level study of the causes of traffic accidents. Report No. DOT-HS-034-3-535-77 (TAC).

Türkiye İstatistik Kurumu (2016). Karayolu trafik kaza istatistikleri, 2015. Retrieved from: http://www.tuik.gov.tr/PreHaberBultenleri.do?id=21611

Weiss, H. B., Kaplan, S. ve Prato, C. G. (2014). Analysis of factors associated with injury severity in crashes involving young New Zealand drivers. Accident Analysis and Prevention, 65, 142-155. doi: 10.1016/j.aap.2013.12.020

\section{TQD}

